\title{
Treatment of non-ST-elevation myocardial infarction and ST-elevation myocardial infarction in patients with chronic kidney disease
}

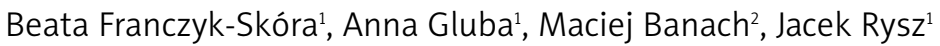

1Department of Nephrology, Hypertension and Family Medicine, WAM University Hospital of Lodz, Poland

2Department of Hypertension, Medical University of Lodz, Poland

Submitted: 25 November 2013

Accepted: 4 December 2013

Arch Med Sci 2013; 9, 6: 1019-1027

DOI: $10.5114 /$ aoms.2013.39792

Copyright $\odot 2013$ Termedia \& Banach

\section{Abstract}

Renal dysfunction is frequent in patients with non-ST-segment elevation acute coronary syndrome (NSTE-ACS). Chronic kidney disease (CKD) is associated with very poor prognosis and is an independent predictor of early and late mortality and major bleeding in patients with NSTE-ACS. Patients with NSTE-ACS and CKD are still rarely treated according to guidelines. Medical registers reveal that patients with CKD are usually treated with too high doses of antithrombotics, especially anticoagulants and inhibitors of platelet glycoprotein (GP) Ilb/IIla receptors, and therefore they are more prone to bleeding. Drugs which are excreted mainly or exclusively by the kidney should be administered in a reduced dose or discontinued in patients with CKD. These drugs include enoxaparin, fondaparinux, bivalirudin, and small molecule inhibitors of GP IIb/IIla inhibitors. In long-term treatment of patients after myocardial infarction, anti-platelet therapy, lipid-lowering therapy and $\beta$-blockers are used. Chronic kidney disease patients before qualification for coronary interventions should be carefully selected in order to avoid their use in the group of patients who could not benefit from such procedures. This paper presents schemes of non-ST and ST-segment elevation myocardial infarction treatment in CKD patients in accordance with the current recommendations of the European Society of Cardiology (ESC).

Key words: bleeding, chronic kidney disease, management, myocardial infarction, treatment.

\section{Introduction}

Renal dysfunction is present in $30-40 \%$ of patients with non-STsegment elevation acute coronary syndrome (NSTE-ACS) [1, 2]. In patients with chronic kidney disease (CKD), heart failure (HF) with lack of typical chest pain is frequent [3]. Chronic kidney disease is usually associated with very poor prognosis [1, 2, 4] and is an independent predictor of early and late mortality and major bleeding in patients with NSTE-ACS [2]. According to studies the risk of cardiac death is increased $46 \%$ in those with a glomerular filtration rate (GFR) between $60 \mathrm{ml} / \mathrm{min}$ and $90 \mathrm{ml} / \mathrm{min}$ and $131 \%$ in those with GFR between $30 \mathrm{ml} / \mathrm{min}$ and $60 \mathrm{ml} / \mathrm{min}$, independent of traditional cardiovascular (CV) risk factors including diabetes and hypertension $[5,6]$. Biomarkers of CKD (such as proteinuria, estimated GFR (eGFR) $[7,8])$ are easy and relatively inexpensive to detect, and

\author{
Corresponding author: \\ Beata Franczyk-Skóra MD, \\ $\mathrm{PhD}$ \\ Department of Nephrology, \\ Hypertension and Family \\ Medicine \\ WAM University Hospital \\ of Lodz \\ 113 Zeromskiego St \\ 90-549 Lodz, Poland \\ E-mail: beata.franczyk- \\ skora@umed.lodz.pl
}


there is evidence that screening for CKD in global health programs will significantly improve the outcomes of not only renal disease, but also diabetes and CVD [5]. Moreover, more attention should be put on the treatment of CKD patients with NSTEACS since they are rarely treated according to guidelines.

\section{Non-ST-elevation myocardial infarction in chronic kidney disease patients}

Although patients with NSTE-ACS and CKD are often underrepresented in clinical trials, there is no particular rationale to treat them in a different way than patients without renal dysfunction. However, due to the risk of bleeding complications, anticoagulation therapy should be used with caution.

According to data from medical registers, patients with CKD are frequently treated with too high doses of antithrombotics, especially anticoagulants and inhibitors of platelet glycoprotein (GP) $\mathrm{Ilb} / \mathrm{lll}$ a receptors, and therefore they are more prone to bleeding. According to studies, aspirin can be safely and effectively used in patients with CKD in the management of acute coronary syndromes without the need for dose modification [9].
Many drugs which are excreted mainly or exclusively by the kidney should be administered in a reduced dose or discontinued in patients with CKD. These drugs include enoxaparin, fondaparinux, bivalirudin, and small molecule inhibitors of GP IIb/IIla inhibitors (Table I).

In severe renal failure, when fondaparinux or enoxaparin is contraindicated, unfractionated heparin (UFH) use is recommended. According to the GRACE (Global Registry of Acute Coronary Events) registry UFH does not protect against bleeding complications. In patients receiving UFH, a gradual increase in the bleeding risk along with the progression of renal dysfunction is observed. The same tendency was seen in the case of low-molecularweight heparin (LMWH) use [10]. The EXTRACT (Enoxaparin and Thrombolysis Reperfusion for Acute Myocardial Infarction Treatment)-TIMI 25 sub-study demonstrated that every $30 \mathrm{ml} / \mathrm{min}$ decrease in creatinine clearance $(\mathrm{CrCl})$ increased the risk of major and minor bleeding by $50 \%$ [11]. The benefits of UFH therapy in CKD patients in comparison to other antithrombotics are associated with the fact that while using UFH anticoagulant activity can be easily monitored on the basis of activated partial throm-

Table I. Recommendations concerning the use of antithrombotic drugs in patients with chronic kidney disease according to ESC guidelines

\begin{tabular}{|c|c|}
\hline \multicolumn{2}{|l|}{ Antiplatelet therapy } \\
\hline ASA & Lack of specific recommendations \\
\hline Clopidogrel & Lack of recommendations for CKD patients \\
\hline \multirow[t]{2}{*}{ Prasugrel } & Lack of information concerning the reduction of dose in patients with GFR $30-60 \mathrm{ml} / \mathrm{min} / 1.73 \mathrm{~m}^{2}$ \\
\hline & Contraindicated in patients with GFR $<30 \mathrm{ml} / \mathrm{min} / 1.73 \mathrm{~m}^{2}$ \\
\hline Ticagrelor & There is no need to adjust the dose in CKD patients \\
\hline \multicolumn{2}{|l|}{ GPIIb/Illa antagonists } \\
\hline Abciximab & Lack of recommendations concerning the use or dose reduction in CKD patients \\
\hline Tirofiban & $\begin{array}{l}\text { In CKD patients the dose should be reduced; } 50 \% \text { of the standard dose should be used in } \\
\text { patients with GFR }<30 \mathrm{ml} / \mathrm{min} / 1.73 \mathrm{~m}^{2}\end{array}$ \\
\hline \multirow[t]{2}{*}{ Eptifibatide } & $\begin{array}{l}\text { It should be used with caution in CKD patients. Dose reduction in patients with } \\
\text { GFR }<50 \mathrm{ml} / \mathrm{min} / 1.73 \mathrm{~m}^{2} \text { by } 25 \% \text { is required }\end{array}$ \\
\hline & Contraindicated in patients with GFR $<30 \mathrm{ml} / \mathrm{min} / 1.73 \mathrm{~m}^{2}$ \\
\hline \multicolumn{2}{|l|}{ Antithrombotic therapy } \\
\hline $\begin{array}{l}\text { Unfractionated } \\
\text { heparin }\end{array}$ & $\begin{array}{l}\text { The dose should be adjusted (reduced) on the basis of frequently measured aPTT in order } \\
\text { to maintain drug efficiency }\end{array}$ \\
\hline \multirow{3}{*}{$\begin{array}{l}\text { Enoxaparin and } \\
\text { other low molecular } \\
\text { weight heparins }\end{array}$} & In CKD patients with GFR $30-60 \mathrm{ml} / \mathrm{min} / 1.73 \mathrm{~m}^{2}$ the dose should be reduced by $25 \%$ \\
\hline & $\begin{array}{l}\text { Either contraindicated in patients with GFR }<30 \mathrm{ml} / \mathrm{min} / 1.73 \mathrm{~m}^{2} \text { or } 50 \% \text { dose reduction } \\
\text { is required depending on drug registration in the given country }\end{array}$ \\
\hline & Therapeutic concentration can be controlled on the basis of anti-Xa activity \\
\hline \multirow[t]{2}{*}{ Fondaparinux } & $\begin{array}{l}\text { Drug of choice in patients with GFR } 30-60 \mathrm{ml} / \mathrm{min} / 1.73 \mathrm{~m}^{2} \text { due to lower risk of bleeding } \\
\text { complications in comparison to enoxaparin }\end{array}$ \\
\hline & Contraindicated in patients with GFR $<30 \mathrm{ml} / \mathrm{min} / 1.73 \mathrm{~m}^{2}$ \\
\hline \multirow[t]{2}{*}{ Bivalirudin } & In CKD patients with GFR $30 \mathrm{ml} / \mathrm{min} / 1.73 \mathrm{~m}^{2}$ the infusion rate should be reduced to $1.0 \mathrm{mg} / \mathrm{kg} / \mathrm{h}$ \\
\hline & The use of this drug in patients with NSTEMI and CKD should be carefully considered \\
\hline
\end{tabular}


boplastin time (aPTT) level and that it can be quickly neutralized in the case of bleeding. Fondaparinux has a much safer profile than enoxaparin in patients with CKD, as evidenced by significantly lower risk of bleeding complications seen in the OASIS- 5 trial. In the PLATO (Study of Platelet Inhibition and Patient Outcomes) study, ticagrelor significantly reduced the incidence of ischemic end points and mortality in comparison to clopidogrel, without increasing the risk of major bleeding $[12,13]$. It was thought that clopidogrel, which is metabolized in the liver, requires no dose adjustment in patients with renal failure. However, a sub-study of the Clopidogrel for the Reduction of Events During Observation (CREDO) trial demonstrated that clopidogrel may have decreased effectiveness in patients with mild-tomoderate CKD and that this effect was not related to increased bleeding in that group [14]. Also Park et al. [15], who compared the responsiveness of clopidogrel in CKD patients and healthy persons, observed that platelet inhibition was decreased in patients with renal insufficiency, even when doubling the dose of clopidogrel. The scheme of ACS treatment in CKD patients with the division into high and low risk patients (according to European Society of Cardiology (ESC) recommendations) is presented in Figure $1[16,17]$.

The analyses of data from large registry and clinical trials concerning NSTE-ACS revealed that improved prognosis of patients with CKD following invasive treatment was observed not only in endstage renal disease, but also in patients with moderate CKD [16, 17]. Observational studies demonstrated that the implementation of invasive treatment is associated with better 1-year survival in patients with mild to moderate kidney disease. However, these benefits became less pronounced as renal function decreased and were doubtful in patients with renal failure or on dialysis. It should also be kept in mind that CKD patients are at risk of contrast-induced nephropathy. This risk is much higher in the elderly and in patients with diabetes. In the case of emergency angiography the ratio between the risk of contrast-induced nephropathy and risk of ischemia should be assessed. It was shown that proper irrigation of the patient $12 \mathrm{~h}$ before and $24 \mathrm{~h}$ after angiography or angioplasty has the greatest impact on reduction of the risk of contrast-induced nephropathy. The amount of contrast medium should be maintained at $<4 \mathrm{ml} / \mathrm{kg}[18,19]$.

\section{ST-elevation myocardial infarction in chronic kidney disease patients}

The reduction in GFR increases the risk of serious cardiovascular complications by about $20 \%$ (compared to subjects with normal renal function). A reduction in GFR $<70 \mathrm{ml} / \mathrm{min} / 1.73 \mathrm{~m}^{2}$ is found in approximately $40 \%$ of patients with and[RA1] STsegment elevation myocardial infarction (STEMI). Along with the progression of kidney damage the risk of serious complications such as heart failure, cardiac shock, cardiac arrhythmias and atrioventricular block increases. Worse prognosis is also associated with the fact that patients with chronic kidney disease are usually more advanced in age and often suffer from diabetes, coronary artery disease and heart failure [16].

The clinical picture of myocardial infarction (MI) may be similarly atypical in renal failure as in diabetes. Lower predictive value of commonly used diagnostic markers of myocardial necrosis in patients with chronic kidney disease pose an additional problem $[20,21]$. The treatment of myocardial infarction in patients with chronic kidney disease does not differ significantly from the procedure used in patients with normal renal function. However, many authors recommend more aggressive treatment, particularly angioplasty, as a method of restoration of infarct-related artery patency in CKD patients. The risk of surgery is greater than in the population with normal renal function, but the benefits are much better than in the case of conservative treatment.

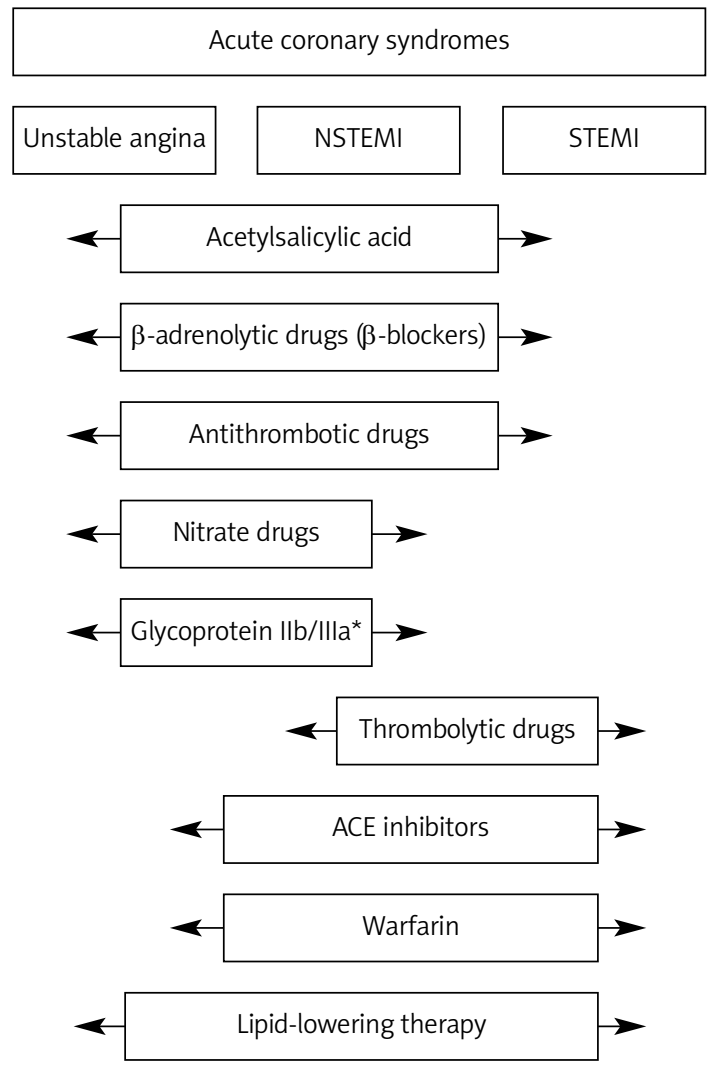

Figure 1. ACS treatment in CKD patients with the division into high and low risk patients according to European Society of Cardiology (ESC) 2011 recommendations

*Indicated for people in high risk group 
The treatment with intravenous antagonists of GP IIb/IIla in patients with CKD is associated with a higher risk of bleeding complications, but it also significantly reduces the risk of in-hospital deaths. Treatment with unfractionated heparin with the monitoring of aPTT is recommended in this group of patients. It should be kept in mind that ACE inhibitors and sartans may aggravate renal impairment $[16,17,20]$. According to Swanepoel [20] the use of $\beta$-blockers following ST segment elevation $\mathrm{MI}$ in hemodialysis patients is beneficial and recommended partly due to great sympathetic overactivity of catecholamine release in this group of patients. The scheme of the ESC recommendations concerning ACS treatment in CKD patients is presented in Figure 2.

\section{General long-term treatment (secondary prevention)}

In long-term treatment of patients after $\mathrm{MI}$, antiplatelet therapy, lipid-lowering therapy and $\beta$-blockers are used [21, 22]. According to studies, the rates of aspirin use are low in patients with CKD mainly due to increased risk of bleeding. In the Wright et al. [23] study, the rate of aspirin use was only $61 \%$ in dialysis patients and $74 \%$ in patients with a GFR of $<35 \mathrm{ml} / \mathrm{min}$, compared to $89 \%$ in patients with a normal GFR. The UK-HARP study (Study of Heart and Renal Protection) revealed that the use of lowdose aspirin (100 mg) in severe CKD (pre-dialysis, dialysis or functioning transplant) increased the risk of minor bleeding three-fold ( $15 \%$ vs. $5 \%$ ), but did not influence the rate of major bleeding [24]. The Antithrombotic Trialists' Collaboration (ATT) metaanalysis showed that low-dose aspirin $(75 \mathrm{mg}$ to $160 \mathrm{mg}$ ) is as efficacious as high-dose aspirin (325 mg) beyond the acute phase for secondary prevention of coronary artery disease in patients with CKD and end-stage renal disease [25]. Moreover, another study conducted on 1,000 end-stage renal disease (ESRD) patients and 145,000 controls who underwent $\mathrm{MI}$ revealed that the efficacy and benefit of aspirin treatment for 30-day mortality were similar to those in patients with normal renal func-

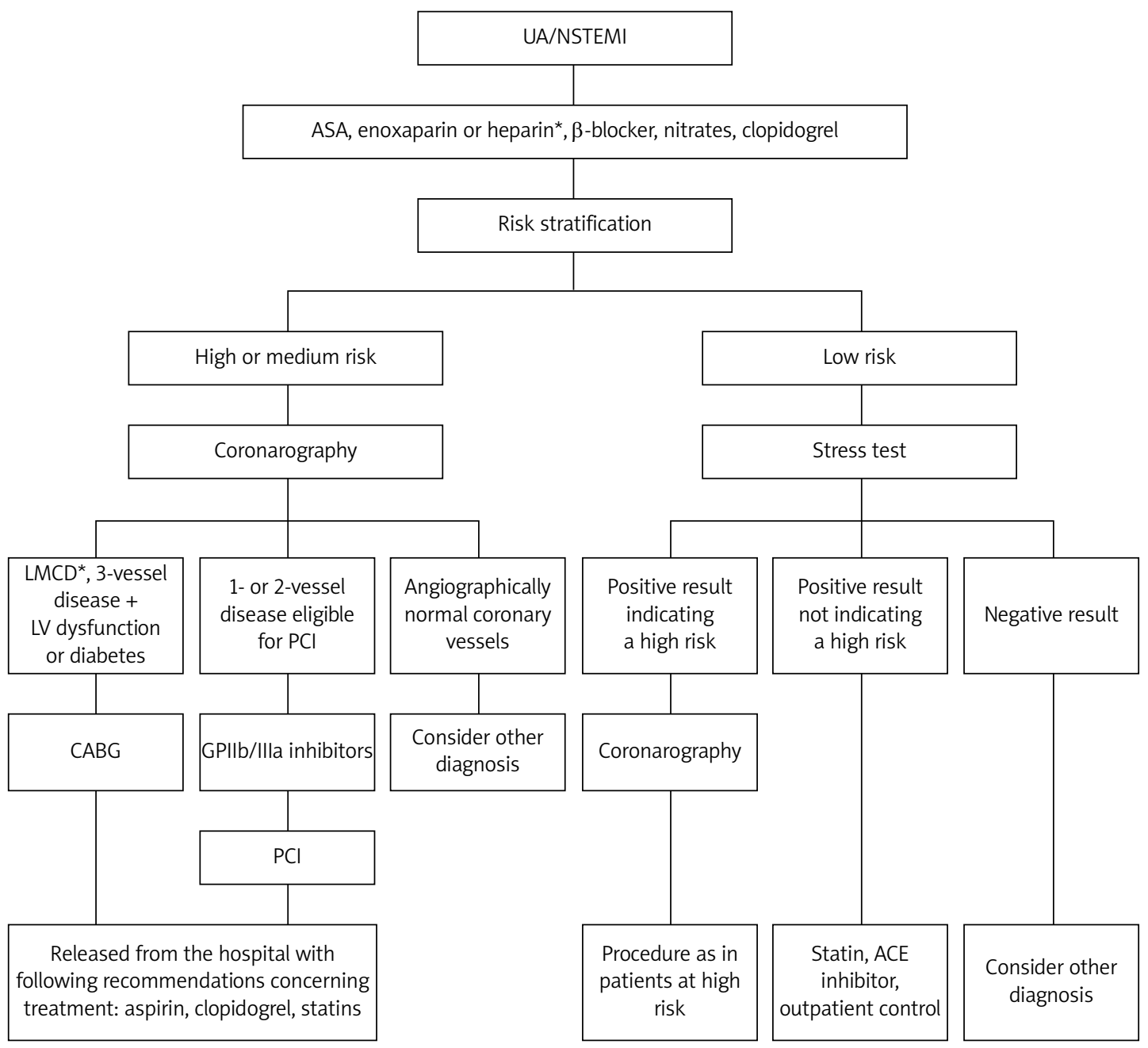

Figure 2. The ESC recommendations concerning ACS management in CKD patients

*Enoxoparin is used in conservative theraphy, while unfractioned heparin in early invasive treatment 
tion [26]. Another retrospective study of patients with ACS demonstrated that the use of aspirin was associated with a decreased rate of STEMI in patients with GFR $<60 \mathrm{ml} / \mathrm{min}$ (odds ratio (OR) 0.5, 95\% Cl 0.2-1.0; $p=0.05$ ) [27]. However, one study found that in patients with coronary artery disease platelet responsiveness to acetylsalicylic acid was reduced compared to controls without coronary artery disease (CAD) [28].

The efficacy of anti-platelet therapy with parenteral GP IIb/IIla inhibitors in patients with CKD is not established. The ESPIRIT study (Enhanced Suppression of the Platelet IIb/IIla Receptor with Integrin Therapy) [29] demonstrated that eptifibatide therapy during percutaneous coronary intervention $(\mathrm{PCI})$ in CKD patients reduced the number of CAD events and the need of further revascularization procedures over the next 12 months to the same degree as in the non-CKD population. Moreover, no increase in the risk of bleeding was observed in this study [29]. However, Freeman et al. [30] demonstrated doubled risk of major bleeding following the use of GP Ilb/IIla. Despite this adverse event, they still observed reduced in-hospital mortality following ACS in CKD patients (eGFR $<60 \mathrm{ml} / \mathrm{min}$ ) [30]. Also, the subanalysis of TARGET (Do Tirofiban and ReoPro Give Similar Efficacy Outcome) study [31] showed that patients with lower $\mathrm{CrCl}$ had more ischemic and bleeding events. Moreover, the PROTECT trial (ProBNP Outpatient Tailored Chronic Heart Failure Therapy) [31] and the CRUSADE (Can Rapid Risk Stratification of Unstable Angina Patients Suppress Adverse Outcomes With Early Implementation of the American College of Cardiology/American Heart Association Guidelines) National Quality Improvement Registry demonstrated that bleeding risk was higher in patients receiving excess doses of GP IIb/IIla inhibitors (OR: 1.36; 95\% Cl: 1.10-1.68), and it is further increased in patients with renal insufficiency (OR 4.12; 95\% Cl: 2.65-5.75) [32, 33].

The use of ACE inhibitors is according to guidelines recommended within $24 \mathrm{~h}$ in all patients with left ventricular ejection fraction (LVEF) $\leq 40 \%$ and in patients with HF, hypertension or CKD unless contraindicated [34, 35]. Angiotensin-convertingenzyme inhibitors (ACEI) should be used to avoid recurrent ischemic events and their efficient types and doses should be applied [36]. In the Heart Outcomes Prevention Evaluation (HOPE) study, ramipril treatment of CKD patients resulted in similar reduction in the frequency of cardiovascular events to that seen in people with normal renal function [37]. Moreover, the CKD group benefited more from ACEI therapy when the influence of ramipril on total mortality, heart failure related hospitalization and cardiovascular mortality was considered. This therapy was not associated with increased risk of acute renal failure [37]. The use of ACEI in dialysis patients should be carefully weighed since experimental data concerning such therapy are conflicting. A small, retrospective study revealed that dialysis patients treated with an ACE inhibitor had a 52\% relative risk reduction for mortality over 5 years $(p<0.0019)$ [38]. However, the prospective Fosinopril in Dialysis (FOSIDIAL) study demonstrated no differences in cardiovascular deaths or morbidity rates (heart failure hospitalization/non-fatal cardiovascular events) over the 2-year follow-up [39, 40].

In patients who do not tolerate ACEI, $\beta$-blockers should be used [40]. $\beta$-Blockers are also recommended in all patients with dysfunction of LV systolic function (LVEF $\leq 40 \%)[41,42]$. The study of McCullough et al. [43] demonstrated that across the range of GFR values, combined effects of $\beta$-blockers and aspirin were associated with reduced in-hospital mortality after NSTEMI by $78 \%$ in patients on dialysis, $64.3 \%$ in those with GFR < $46 \mathrm{ml} / \mathrm{min}, 69 \%$ in those with GFR 46-63 $\mathrm{ml} / \mathrm{min}$, and $75 \%$ in those with GFR $63-81.5 \mathrm{ml} / \mathrm{min}$. Better survival (a $22 \%$ reduction in mortality) of dialysis patients treated with $\beta$-blockers after STEMI was observed by Berger et al. [26]. Moreover, retrospective analysis revealed a lower risk of new heart failure and cardiac death (adjusted hazard ratio $(\mathrm{aHR}) 0.77, p=0.02$ ) as a result of $\beta$-blocker treatment [44].

Statin therapy should be used soon after admission to hospital [45]. The target concentration of low-density lipoprotein cholesterol (LDL-C) was established at $<1.8 \mathrm{mmol} / \mathrm{l}$ [46]. Post hoc analysis of lipid-lowering trials, enrolling patients with mild CKD, revealed that the effects of statins may be comparable with those observed in patients with normal renal function $[47,48]$. According to a retrospective sub-group analysis from the Cholesterol And Recurrent Events (CARE) trial [49], pravastatin reduced cardiovascular death and non-fatal MI. Another retrospective analysis of pravastatin intervention trials demonstrated that it reduced relative risk in patients with CKD (eGFR 30-59 $\mathrm{ml} / \mathrm{min}$ ) in a similar manner to that observed in the overall trial cohorts, including a reduction in total mortality [50]. Analysis of data concerning the use of statins in hemodialysis patients revealed that they were safe for dialysis patients and that they might reduce the incidence of CV deaths by $36 \%$ [51, 52]. However, Deutsche Diabetes Dialyse Studie (4D), in which hemodialysis patients with diabetes obtained either atorvastatin or placebo, failed to show any significant difference in the CV event rate or total mortality in the treatment group over a follow-up period of 5 years [53]. On the other hand, the Lescol Intervention Prevention Study (LIPS) demonstrated that CKD patients (eGFR $<55.9 \mathrm{ml} / \mathrm{min}$ ) undergoing percutaneous coronary intervention $(\mathrm{PCl})$ gained near equal benefit from statin therapy to that seen 
in patients with normal renal function [54]. The most recent meta-analyses from the Lipid and Blood Pressure Meta-Analysis Collaboration (LBPMC) Group suggest univocally that statins are very effective, in terms of lipid parameters, renal outcomes, as well as cardiovascular endpoints and all-cause mortality, only in patients without renal replacement therapy. What is more, it seems that longterm therapy with statins in dialysis patients might even worsen the lipid parameters. Therefore the authors do not recommend initiating statin treatment in ESRD patients requiring dialysis. On the other hand, they suggest that there are not enough data to stop treatment in patients who are already on statins. They also emphasize that large, welldesigned, randomized trials in well-selected CKD patients on dialysis are necessary, in order to finally confirm or refute the limited benefits of statin therapy [55-58]. These data are strictly in line with the most recent KDIGO recommendation [59].

\section{Myocardial revascularization in patients with chronic kidney disease}

\section{Patients with chronic kidney disease with glomerular filtration rate $30-90 \mathrm{ml} / \mathrm{min} / 1.73 \mathrm{~m}^{2}$}

According to recommendations, coronary artery bypass grafting (CABG) is a better way of treatment than $\mathrm{PCl}$, especially when CKD is a result of diabetes. When surgical revascularization is required, surgery without cardiopulmonary bypass can be considered [60]. If there are indications for $\mathrm{PCl}$, there is weak evidence that drug-eluting stents (DES) are more beneficial than bare-metal stents (BMS) since their implantation is associated with

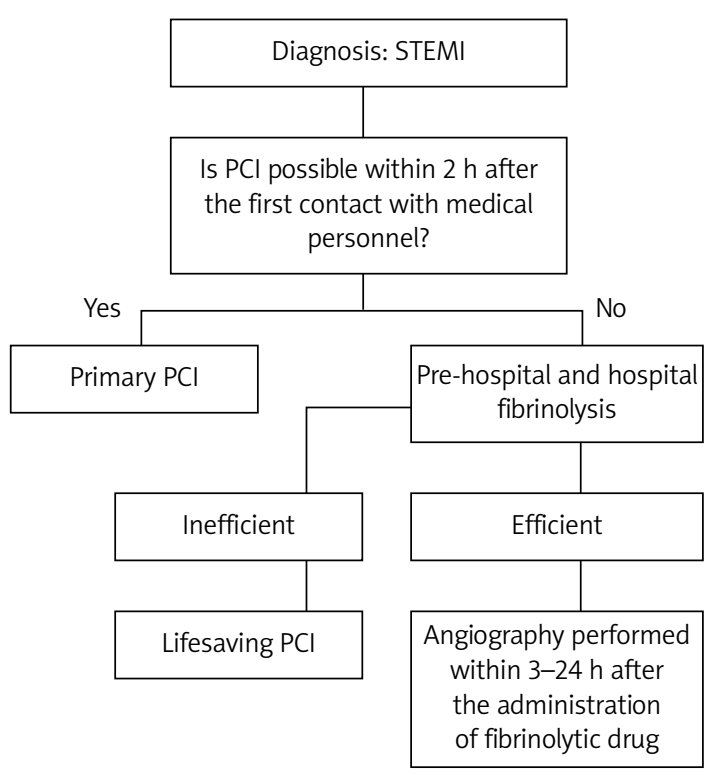

Figure 3. Schemes of invasive treatment in accordance with recommendations of European Society of Cardiology lower frequency of recurrent ischemic events. However, it should be kept in mind that DES implantation is associated not only with benefits but also with some adverse effects due to the need for longterm use of dual antiplatelet therapy as well as increased risk of late thrombosis and higher susceptibility to restenosis in complex calcified changes. Percutaneous coronary intervention in CKD patients is associated with increased risk of death and major adverse cardiac events during and after the procedure and this risk rises gradually with the degree of renal impairment [61]. Patients with CKD often experience periprocedural MI, ischemia and target vessel revascularization [62].

\section{Patients with severe chronic kidney disease (GFR $<30 \mathrm{ml} / \mathrm{min} / 1.73 \mathrm{~m}^{2}$ ), end-stage renal disease or on hemodialysis}

The benefits of CABG treatment in comparison to $\mathrm{PCl}$ are less unequivocal. Surgical treatment is associated with better survival in long-term observation, but in-hospital mortality and the incidence of complications are greater. When choosing the most appropriate revascularization strategy, the patient's general condition and his life expectancy must be considered. In patients in a very serious general condition and in those most susceptible to complications, the least invasive treatment should be carried out. In these patients, no advantages of DES over BMS were found and they all should not be used without limitations [60]. Patients eligible for kidney transplantation should be screened to assess the incidence of myocardial ischemia. Patients with significant CAD should not be deprived of the potential benefits of myocardial revascularization. If kidney transplantation is possible during a year, $\mathrm{PCl}$ with $\mathrm{BMS}$ implantation should be considered $[63,64]$.

The Global Registry of Acute Coronary Events (GRACE) study confirmed higher mortality and lower reperfusion rates in patients with CKD undergoing primary $\mathrm{PCI}$ for STEMI. It demonstrated that adverse outcomes became more frequent along with renal function deterioration [65]. Dewey et al. [66] in their study demonstrated that off-pump revascularization in patients with ESRD on hemodialysis is associated with better perioperative morbidity and mortality compared with conventional surgery with cardiopulmonary bypass (CPB). However, their results clearly indicated that longterm survival was significantly better in the onpump patients, probably due to incomplete revascularization in the off-pump cohort. Moreover, revascularization with the use of CPB was shown to increase the life expectancy of patients with ESRD and coronary artery disease in comparison to patients with no interventions [66]. 
Chronic kidney disease patients before qualification for CABG should be carefully selected in order to avoid its use in the group of patients who could not benefit from such a procedure. Moreover, patients who underwent off-pump bypass grafting should be followed up to ensure that the benefits seen in the perioperative period translate into longterm results equivalent to conventional revascularization [66]. Schemes of invasive treatment in accordance with recommendations of the ESC are presented in Figure 3.

\section{Conclusions}

Non-ST elevation myocardial infarction and STEMI occur frequently in CKD patients. Although the results of numerous studies and meta-analyses are conflicting, it seems that CKD patients should not be deprived of standard cardiovascular treatment but the doses ought to be titrated to avoid adverse effects. Also the standard procedures should be implemented in CKD patients but only in those in whom the benefits outweigh the risks [67-74].

\section{References}

1. Hasdai D, Behar S, Wallentin L, et al. A prospective survey of the characteristics, treatments and outcomes of patients with acute coronary syndromes in Europe and the Mediterranean basin: the Euro Heart Survey of Acute Coronary Syndromes. Eur Heart J 2002; 23: 1190-201.

2. Goldenberg I, Subirana I, Boyko V, et al. Relation between renal function and outcomes in patients with non-ST segment elevation acute coronary syndrome: real-world data from the European Public Health Outcome Research and Indicators Collection Project. Arch Intern Med 2010; 170: 888-95.

3. Szummer K, Lundman P, Jacobson SH, et al. Relation between renal function, presentation, use of therapies and in-hospital complications in acute coronary syndrome: data from the SWEDEHEART register. J Inter Med 2010; 268: 40-9.

4. Franczyk-Skóra B, Gluba A, Banach M, Kozłowski D, Małyszko J, Rysz J. Prevention of sudden cardiac death in patients with chronic kidney disease. BMC Nephrol 2012; 13: 162.

5. Couser WG, Riella MC. World Kidney Day 2011 - Protect your kidneys, save your heart. Arch Med Sci 2011; 7: 1-4.

6. van Domburg RT, Hoeks SE, Welten GMJM, Chonchol M, Elhendy A, Poldermans D. Renal insufficiency and mortality in patients with known or suspected coronary artery disease. J Am Soc Neph 2008; 19: 158-63

7. Malyszko J, Bachorzewska-Gajewska H, Malyszko J, lainaLevin N, Kobus G, Dobrzycki S. Markers of kidney function in the elderly in relation to the new CKD-EPI formula for estimation of glomerular filtration rate. Arch Med Sci 2011; 7: 658-64.

8. Nair DR, Mehta S, Mikhailidis DP. Assessing renal function - searching for the perfect marker continues! Arch Med Sci 2011; 7: 565-7.

9. Coats WC, Baig SZ, Alpert MA, Aggarwal K. Management of coronary artery disease in patients with chronic kidney disease. Adv Perit Dial 2009; 25: 125-8.

10. Collet JP, Montalescot G, Agnelli G, et al. Non-ST segment elevation acute coronary syndrome in patients with renal dysfunction: benefit of low-molecular-weight heparin alone or with glycoprotein IIb/IIla inhibitors on outcomes. The Global Registry of Acute Coronary Events. Eur Heart J 2005; 26: 2285-93.

11. Fox KA, Antman EM, Montalescot G, et al. The impact of renal dysfunction on outcomes in the ExTRACT-TIMI 25 trial. J Am Coll Cardiol 2007; 49: 2249-55.

12. James S, Budaj A, Aylward P, et al. Ticagrelor versus clopidogrel in acute coronary syndromes in relation to renal function: results from the Platelet Inhibition and Patient Outcomes (PLATO) trial. Circulation 2010; 122: 1056-67.

13. Kowalczyk M, Banach M, Mikhailidis DP, Hannam S, Rysz J. Ticagrelor: a new platelet aggregation inhibitor in patients with acute coronary syndromes. An improvement of other inhibitors? Med Sci Monit 2009; 15: MS24-30.

14. Best PJ, Steinhubl SR, Berger PB, et al. The efficacy and safety of short- and long-term dual antiplatelet therapy in patients with mild or moderate chronic kidney disease: results from the Clopidogrel for the Reduction of Events During Observation (CREDO) trial. Am Heart J 2008; 155: 687-93.

15. Park SH, Kim W, Park CS, Kang WY, Hwang SH, Kim W. A comparison of clopidogrel responsiveness in patients with versus without chronic renal failure. Am J Cardiol 2009; 104: 1292-5.

16. Franczyk-Skóra B, Gluba A, Banach M, Rozentryt P, Poloński L, Rysz J. Acute coronary syndromes in patients with chronic kidney disease. Curr Vasc Pharmacol 2013; 11: 758-67.

17. Hamm CW, Bassand JP, Agewall S, et al.; ESC Committee for Practice Guidelines. ESC Guidelines for the management of acute coronary syndromes in patients presenting without persistent ST-segment elevation: the Task Force for the management of acute coronary syndromes (ACS) in patients presenting without persistent ST-segment elevation of the European Society of Cardiology (ESC). Eur Heart J 2011; 32: 2999-3054.

18. Gluba A, Rysz J, Banach M. Statins in patients with chronic kidney disease: why, who and when? Expert Opin Pharmacother 2010; 11: 2665-74.

19. Barylski M, Małyszko J, Rysz J, Myśliwiec M, Banach M. Lipids, blood pressure, kidney - what was new in 2011? Arch Med Sci 2011; 7: 1055-66.

20. Swanepoel CR. Chronic kidney disease is a risk factor for cardiovascular disease. SA Heart J 2007; 4: 38-43.

21. Mercando AD, Lai HM, Aronow WS, et al. Reduction in atherosclerotic events: a retrospective study in an outpatient cardiology practice. Arch Med Sci 2012; 8: 57-62.

22. Lai HM, Aronow WS, Mercando AD, et al. Risk factor reduction in progression of angiographic coronary artery disease. Arch Med Sci 2012; 8: 444-8.

23. Wright RS, Reeder GS, Herzog CA, et al. Acute myocardial infarction and renal dysfunction: a high-risk combination. Ann Intern Med 2002; 137: 563-70.

24. Baigent C, Landray $M$, Leaper $C$, et al. First United Kingdom Heart and Renal Protection (UK-HARP-I) study: biochemical efficacy and safety of simvastatin and safety of low-dose aspirin in chronic kidney disease. Am J Kidney Dis 2005; 45: 473-84.

25. Collaborative meta-analysis of randomized trials of antiplatelet therapy for prevention of death, myocardial infarction, and stroke in high risk patients. BMJ 2002; 324: 71-86.

26. Berger AK, Duval S, Krumholz HM. Aspirin, beta-blocker, and angiotensin-converting enzyme inhibitor therapy in 
patients with end-stage renal disease and an acute myocardial infarction. J Am Coll Cardiol 2003; 42: 201-8.

27. Sciahbasi A, Arcieri R, Quarto M, et al. Impact of chronic aspirin and statin therapy on presentation of patients with acute myocardial infarction and impaired renal function. Prev Cardiol 2010; 13: 18-22.

28. Markuszewski L, Rosiak M, Golanski J, Rysz J, Spychalska M, Watala C. Reduced blood platelet sensitivity to aspirin in coronary artery disease: are dyslipidaemia and inflammatory states possible factors predisposing to suboptimal platelet response to aspirin? Basic Clin Pharmacol Toxicol 2006; 98: 503-9.

29. Reddan DN, O'Shea JC, Sarembock IJ, et al. Treatment effects of eptifibatide in planned coronary stent implantation in patients with chronic kidney disease (ESPRIT Trial). Am J Cardiol 2003; 91: 17-21.

30. Freeman RV, Mehta RH, Al Badr W, Cooper JV, KlineRogers E, Eagle KA. Influence of concurrent renal dysfunction on outcomes of patients with acute coronary syndromes and implications of the use of glycoprotein Ilb/Illa inhibitors. J Am Coll Cardiol 2003; 41: 718-24.

31. Berger PB, Best PJM, Topol EJ, et al. The relation of renal function to ischemic and bleeding outcomes with 2 different glycoprotein IIb/IIla inhibitors: the do Tirofiban and ReoPro Give Similar Efficacy Outcome (TARGET) trial. Am Heart J 2005; 149: 869-75.

32. Kirtane AJ, Piazza G, Murphy SA, et al. Correlates of bleeding events among moderate- to high-risk patients undergoing percutaneous coronary intervention and treated with eptifibatide: observations from the PROTECTTIMI-30 trial. J Am Coll Cardiol 2006; 47: 2374-9.

33. Alexander KP, Chen AY, Roe MT, et al. Excess dosing of antiplatelet and antithrombin agents in the treatment of non-ST-segment elevation acute coronary syndromes. JAMA 2005; 294: 3108-16.

34. Basra SS, Tsai P, Lakkis NM. Antiplatelet and anti thrombotic therapy in ACS patients with CKD: antiplatelet and antithrombotic drugs. J Am Coll Cardiol 2011; 58: 2263-9.

35. Torp-Pedersen C, Kober L. Effects of ACE inhibitor trandolapril on life expectancy of patients with reduced LVEF after acute myocardial infarction. TRACE Study Group. Trandolapril Cardiac Evaluation. Lancet 1999; 354: 9-12.

36. Dagenais GR, Pogue J, Fox K, Simoons ML, Yusuf S Angiotensin-converting enzyme inhibitors in stable vascular disease without left ventricular systolic dysfunction or heart failure: a combined analysis of three trial. Lancet 2006; 368: 581-8.

37. Mann JF, Gerstein HC, Pogue J, Bosch J, Yusuf S. Renal insufficiency as a predictor of cardiovascular outcomes and the impact of ramipril: the HOPE randomized trial. Ann Intern Med 2001; 134: 629-36.

38. Efrati S, Zaidenstein R, Dishy V, et al. ACE inhibitors and survival of hemodialysis patients. Am J Kidney Dis 2002; 40: 1023-9.

39. Coletta AP, Cleland JG, Freemantle N, Clark AL. Clinical trials update from the European Society of Cardiology Heart Failure meeting: SHAPE, BRING-UP 2 VAS, COLA II, FOSIDIAL, BETACAR, CASINO and meta-analysis of cardiac resynchronisation therapy. Eur J Heart Fail 2004; 6: 673-6.

40. Zannad F, Kessler M, Grunfeld JP, Thuilliez C. FOSIDIAL: a randomised placebo controlled trial of the effects of fosinopril on cardiovascular morbidity and mortality in haemodialysis patients. Study design and patients' baseline characteristics. Fundam Clin Pharmacol 2002; 16: 353-60.

41. ONTARGET Investigators; Yusuf S, Teo KK, Pogue J, et al. Telmisartan, ramipril, or both in patients at high risk for vascular events. N Engl J Med 2008; 358: 1547-59.

42. Lopez-Sendon J, Swedberg K, McMurray J, et al. Expert consensus document on beta-adrenergic receptor blockers. Eur Heart J 2004; 25: 1341-62.

43. McCullough PA, Sandberg KR, Borzak S, Hudson MP, Garg M, Manley HJ. Benefits of aspirin and beta-blockade after myocardial infarction in patients with chronic kidney disease. Am Heart J 2002; 144: 226-32.

44. Abbott KC, Trespalacios FC, Agodoa LY, Taylor AJ, Bakris GL. beta-Blocker use in long-term dialysis patients: association with hospitalized heart failure and mortality. Arch Intern Med 2004; 164: 2465-71.

45. Stepien M, Banach M, Mikhailidis DP, Gluba A, Kjeldsen SE, Rysz J. Role and significance of statins in the treatment of hypertensive patients. Curr Med Res Opin 2009; 25: 1995-2005.

46. Cannon CP, Braunwald E, McCabe $\mathrm{CH}$, et al. Pravastatin or Atorvastatin Evaluation and Infection Therapy-Thrombolysis in Myocardial Infarction 22 Investigators. Intensive versus moderate lipid lowering with statins after acute coronary syndromes. N Engl J Med 2004; 350: 1495-504.

47. Edwards NC, Steeds RP, Ferro CJ, Townend JN. The treatment of coronary artery disease in patients with chronic kidney disease. Q J Med 2006; 99: 723-36.

48. Athyros VG, Hatzitolios Al, Karagiannis A, et al.; IMPERATIVE Collaborative Group. IMproving the imPlemEntation of cuRrent guidelines for the mAnagement of major coronary hearT disease rlsk factors by multifactorial interVEntion. The IMPERATIVE renal analysis. Arch Med Sci 2011; 7: 984-92.

49. Tonelli M, Moye L, Sacks FM, Kiberd B, Curhan G. Pravastatin for secondary prevention of cardiovascular events in persons with mild chronic renal insufficiency. Ann Intern Med 2003; 138: 98-104.

50. Tonelli M, Isles C, Curhan GC, et al. Effect of pravastatin on cardiovascular events in people with chronic kidney disease. Circulation 2004; 110: 1557-63.

51. Seliger SL, Weiss NS, Gillen DL, et al. HMG-CoA reductase inhibitors are associated with reduced mortality in ESRD patients. Kidney Int 2002; 61: 297-304.

52. Wanner C, Krane V, Marz W, et al. Atorvastatin in patients with type 2 diabetes mellitus undergoing hemodialysis. N Engl J Med 2005; 353: 238-48.

53. Rysz J, Aronow WS, Stolarek RS, Hannam S, Mikhailidis DP, Banach M. Nephroprotective and clinical potential of statins in dialyzed patients. Expert Opin Ther Targets 2009; 13: 541-50.

54. Lemos PA, Serruys PW, de Feyter P, et al. Long-term fluvastatin reduces the hazardous effect of renal impairment on four-year atherosclerotic outcomes (a LIPS substudy). Am J Cardiol 2005; 95: 445-51.

55. Nikolic D, Nikfar S, Salari P, et al.; Lipid and Blood Pressure Meta-Analysis Collaboration Group. Effects of statins on lipid profile in chronic kidney disease patients: a metaanalysis of randomized controlled trials. Curr Med Res Opin 2013; 29: 435-51

56. Nikolic D, Banach M, Nikfar S, et al.; Lipid and Blood Pressure Meta-Analysis Collaboration Group. A metaanalysis of the role of statins on renal outcomes in patients with chronic kidney disease. Is the duration of therapy important? Int J Cardiol 2013; 168: 5437-47.

57. Barylski M, Nikfar S, Mikhailidis DP, et al.; Lipid and Blood Pressure Meta-Analysis Collaboration Group. Statins 
decrease all-cause mortality only in CKD patients not requiring dialysis therapy: a meta-analysis of 11 randomized controlled trials involving 21,295 participants. Pharmacol Res 2013; 72: 35-44.

58. Banach M; Lipid and Blood Pressure Meta-Analysis Collaboration Group. Statins in patients with chronic kidney disease - an attempt at recommendations. Curr Med Res Opin 2013; 29: 1419-22.

59. KDIGO Clinical Practice Guideline for Lipid Management in Chronic Kidney Disease. Kidney Int Suppl 2013; 3: 259-305.

60. Wijns W, Kolh P, Danchin N, et al. Guidelines on myocardial revascularization The Task Force on Myocardial Revascularization of the European Society of Cardiology (ESC) and the European Association for Cardio-Thoracic Surgery (EACTS). Developed with the special contribution of the European Association for Percutaneous Cardiovascular Interventions (EAPCI). Eur Heart J 2010; 31: 2501-55.

61. Best PJ, Lennon R, Ting HH, et al. The impact of renal insufficiency on clinical outcomes in patients undergoing percutaneous coronary interventions. J Am Coll Cardiol 2002; 39: 1113-9.

62. Sica D. The implications of renal impairment among patients undergoing percutaneous coronary intervention. J Invasive Cardiol 2002; 14 (Suppl. B): 30B-7B.

63. Machnicki G, Lentine KL, Salvalaggio PR, Burroughs TE, Brennan DC, Schnitzler MA. Kidney transplant Medicare payments and length of stay: associations with comorbidities and organ quality. Arch Med Sci 2011; 7: 278-86.

64. Malyszko J, Zbroch E, Malyszko J, Mysliwiec M, laina A. The cardio-renal-anaemia syndrome predicts survival in peritoneally dialyzed patients. Arch Med Sci 2010; 6: 539-44.

65. Medi C, Montalescot G, Budaj A, et al. Reperfusion in patients with renal dysfunction after presentation with ST-segment elevation or left bundle branch block. JACC Cardiovasc Interv 2009; 2: 26-33.

66. Dewey TM, Herbert MA, Prince SL, et al. Does coronary artery bypass graft surgery improve survival among patients with end-stage renal disease? Ann Thorac Surg 2006; 81: 591-8.

67. Koc-Zorawska E, Malyszko J, Zbroch E, Malyszko J, Mysliwiec M. Vascular adhesion protein-1 and renalase in regard to diabetes in hemodialysis patients. Arch Med Sci 2012; 8: 1048-52.

68. Olechnowicz-Tietz S, Gluba A, Paradowska A, Banach M, Rysz J. The risk of atherosclerosis in patients with chronic kidney disease. Int Urol Nephrol 2013; 45: 1605-12.

69. Babińska M, Holecki M, Prochaczek F, et al. Is plasma urotensin II concentration an indicator of myocardial damage in patients with acute coronary syndrome? Arch Med Sci 2012; 8: 449-54.

70. Banach M, Mikhailidis DP, Kjeldsen SE, Rysz J. Time for new indications for statins? Med Sci Monit 2009; 15: MS1-5.

71. Marenzi G, Cabiati A, Assanelli E. Chronic kidney disease in acute coronary syndromes. World J Nephrol 2012; 1: 134-45.

72. Banach M, Rysz J. Current problems in hypertension and nephrology. Expert Opin Pharmacother 2010; 11: 2575-8.

73. Malyszko J, Banach M. Prediabetes, prehypertension- do we need pre-CKD? Curr Vasc Pharmacol 2014; doi: 10.2174/15701611113119990123

74. Fox CS, Muntner P, Chen AY, et al.; Acute Coronary Treatment and Intervention Outcomes Network registry. Use of evidence-based therapies in short-term outcomes of ST-segment elevation myocardial infarction and non-STsegment elevation myocardial infarction in patients with chronic kidney disease: a report from the National Cardiovascular Data Acute Coronary Treatment and Intervention Outcomes Network registry. Circulation 2010; 121: 357-65. 